\title{
John Fiske's Semiotic Analysis in the Spotlight Film
}

\author{
Meutia Sabarini \\ Diponegoro University \\ Email: meutiasabarini@gmail.com \\ *corresponding author
}

\author{
Keywords: \\ Journalist, Film Analysis, \\ Mass Media, Mass Media \\ Representation Mass Media \\ Practice
}

\begin{abstract}
Freedom of the press has become one of the most discussed topics being questioned in the practical, whether it exists. Another issue the press has been facing is that the images of journalists shown in the films are bad. A metaanalysis study concluded a relationship between the image of reality from the film and people's behavior in responding to it. Journalists in a film are generally shown as rude characters. Therefore, to better explain the topic of journalism contained in a film, this article will discuss The Spotlight Film. The film pictured these issues that the press and its journalists usually face in serving the public with accurate and credible information. This study uses a qualitative descriptive design and John Fiske's semiotic theory in analyzing that containing clear and detailed information related to data in the form of descriptions. The result of this study shows 1) In the reality level of John Fiske's theory, The Spotlight showed that journalists base their coverage on accredited sources as their role as a mass media that functions to support social change with access to reliable news sources which are then conveyed to the broader community. 2) At the representation level, the State of Play further reinforces the image of the media and its power. It portrayed the press as heroic and helped legitimize its position as an institution. 3) At the ideology level, the film relies heavily on toxic news values, best described as journalists' hunches. The Spotlight described an extensive investigative process that most newsrooms do not follow, as modern newsgathering occurs mainly in news agencies and press releases.
\end{abstract}

This is an open access article under the CC-BY-SA license.

\section{INTRODUCTION}

Freedom of the press has become one of the most discussed topics which are being questioned in the practical, whether it exists or not. Although press freedom has been proclaimed in various parts of the world, the fact does not show so. Social power took a considerable part of the press world. Although the press's function is to serve society with reality, not all of the reality can be well informed. It is caused by the intervention of the people related to reality. They usually have power, whether in money, social support, or both. This issue has been haunting the press world until now.

At the global level, the concept of global journalism expresses various ideas and suggestions for how news media and journalism education ought to develop in a world characterized by increasing global interdependency among world regions and nations. Often, it is based on a critique of national container thinking. In an increasingly globalized world, most news media still stick too closely to a national outlook on society and accordingly fail to place both domestic and foreign realities in broader transnational contexts (Leuven, 2015).

Another issue that the press has been facing is that the images of journalists shown in the films are bad. A metaanalysis study concluded a relationship between the image of reality from the film and people's behavior in responding to it. Journalists in a film are generally shown as rude characters who meet reporters under mysterious circumstances in dark alleys who risk each character's lives and personal lives to find the truth. Such encounters are not commonly applied in real life because the investigative work of journalists is much more dramatic (Jauhola, 2017). The depiction of journalists' 
fictional work can distort public understanding about journalists and themselves, whereas films can also reveal elements of the journalist's character (Green \& Clark, 2013).

The film currently occupies a significant position as a production medium that is often enjoyed by the public. In the current century, the development of existing technology has continuously attracted societies to mass media. When focusing on the substance or problem presented by a file, various kinds of data will be found that contain the influence of a film on the broader society (Yang, Salmon, Pang, \& Cheng, 2015). A film may also have a significant influence on beliefs, opinions, stereotypes, and individual behavior. Changes in behavior for groups of individuals lead to new opinions on a problem (Shehata \& Strömbäck, 2013).

Therefore, to better explain the topic of journalism contained in a film, this article will discuss The Spotlight Film, a crime drama film based on a true story released in 2015. The film tells a story of an investigative team from mass media trying to find the truth of a sexual harassment case at a house of worship. The film pictured these issues that the press and its journalists usually face in serving the public with accurate and credible information whether they need to back up because the pieces of information are about an organization with power. Alternatively, to fight them for the society's needs and occupy their function as press, while the press itself does not have a good image on public's perspective compared to the church.

The current study had discussed the representation of mass media through The Spotlight film using John Fiske's theory and the nine elements of journalistic (Takziyyah, 2017). While the journalistic elements limited the current study's discussion, this study will focus on the discussions of the mass media and its function for society and the challenges in a broader way.

\section{LITERATURE REVIEW}

\section{A. Mass Media}

Mass media, on its function, is to share factual pieces of information to the public. Saputri (2021) said that mass media is a communication tool that can substantially convey messages and ideas broadly. It is considered a sharp tool that can be used to construct human reality in social life. Moreover, Bungin (2006) stated that mass media could be interpreted as a medium of communication and information that carries out activities in mass dissemination of information and can be accessed by the general public. Mass media is a tool or means to disseminate the essence of news, opinion, commentary, and entertainment when viewed in terms of its meaning. The media is a tool or means used in conveying messages from communicators to the public (Habibi, 2018). In comparison, the definition of mass media itself is a tool used to deliver messages from trusted sources to the public using communication tools including newspapers, films, radio, and television.

\section{B. Mass Media Function}

This paper discusses the implementations of mass media theories about the function of the mass media as a supporter of social changes, which covers: First, the mass media serves as a provider of information. The function of delivering information can be carried out by the mass media concerned. Without the participation of the media, the information cannot be conveyed accurately and quickly. Second, the mass media serves as a decision-maker. In this case, the mass media acts as a party that requires a discussion group whose task is to help make decisions regarding the information to be conveyed. In addition, it is expected that there will be changes in attitudes, beliefs, and social norms due to the information conveyed. It means that the mass media plays a role in conveying information as material for discussion, conveying messages from leaders in the community, and clarifying the problems they convey. The third function, the media, serves as an educator. In this case, the mass media can increase public knowledge according to the topic of information presented (Paul, Singh, \& John, 2013). Meanwhile, according to Elvinaro, the function of mass media, as quoted in Habibie's article (2018), is divided into five types, including the following: Surveillance, Interpretation, Linkage, Transmission of Value, and Entertainment.

\section{Agenda Setting Theory}

The Agenda Setting Theory was discovered in 1922 when Walter Lippmann presented his thoughts on the vital role that mass media can play in influencing the setting of specific images in the public's mind. In describing the influence of mass media, Lippmann gives an example of an individual group who should be enemies when their country is at war. Instead of being enemies, without access to war information through the media, a group of individuals can live in harmony on a remote island. Lippmann shows how the mass media can set a particular agenda that can influence public opinion. However, he never used the term agenda-setting theory in his book. Nevertheless, Lippmann still produced the basis for agenda-setting theory (Razinah \& Zain, 2017).

Agenda setting theory is a theory that discusses how mass media influence society and make a particular issue a topic of public discussion. The public agenda is the main focus or central issue of concern to community members or the public. McCombs and Shaw first used the term agenda-setting theory in 1972. This theory describes the relationship between the emphasis placed on the mass media and media audiences or public relations or attributes to the issue. Agenda 
setting theory began to explain how the mass media influence changes in patterns of political behavior during elections.

Furthermore, the theory has encouraged and developed hundreds of explorations of how the mass media discuss and present issues to the public. Not only that, but the discussion also includes how the mass media color an inevitable event for its media audience. Therefore, the mass media can be considered responsible for influencing and shaping public opinion and views. Such influence of the mass media on the agenda or public opinion can occur intentionally or unintentionally.

In the agenda-setting theory, the mass media is believed to not set the public agenda, especially in terms of opinions or attitudes. However, the mass media has specific access in contributing to or influencing society's perceptions, values, focus, and priorities in general. With the influence of mass media like that, the public who consume information from the media tends to form their own opinions or focus on issues considered worthy of being included in their thoughts.

\section{METHOD}

This study uses a qualitative descriptive design that contains clear and detailed information related to data in descriptions. Sources of data are taken from several data relevant to the topic in this study to support the analysis. The data which will be analyzed were collected from two sources, primary sources and secondary sources. The main source of this research is the literary work of The Spotlight film, which contains extrinsic and intrinsic conflicts between characters and. In addition, other sources include several references to either journals or other reading materials that follow theory to support the analysis. Secondary sources of this research are obtained from other researchers who have previously researched research journals, journal articles, literary criticism, and magazines. To collect data, the researcher used the documentation method.

\section{John Fiske's Semiotic Theory}

The subject and the objects of this research are The Spotlight film and the scenes. To obtain the maximum objectivity and sharp analytical results, the researcher prepared an outline of the research and literature reviews, followed by watching the movie The Spotlight and understanding the scenes and the conflicts by taking notes of every compatible aspect related to the research and then recapitulated them based on these levels below which are mentioned in John Fiske's theory (Vera, 2016):

1. Reality level includes appearance, costume, makeup, environment, behavior, way of speaking, movement, and expression.

2. Representation level includes camera, lighting, editing, music, and sound that transmits conventional representation codes, which make up: narrative, conflict, character, action, dialogue, setting, and casting.

3. Ideology levels include individualism, patriarchy, race, class, materialism, or capitalism.

This method is done because Semiotics focuses on how producers create signs and how society generally understands these signs. John's Fiske Semiotic Theory explained that the information contained in each media is essential and depends on the reading provided by the producer or consumer. Therefore, by the collected data, analyzing step could be done to understand the signs. The researcher analyzed the collected data by matching them with related studies and familiar journalist issues.

Semiotics is a method used to analyze signs. Lacey revealed that the semiotic approach provides an analytical instrument for researchers being observed and ideas related to research. Fiske mentions that the signs which appear or are used in the mass media are interrelated to form a meaning. Reality will not simply be formed through signs displayed but comes from senses that have previously been processed according to public references so that each sign will be appreciated differently by each different individual. Therefore, each individual can respond differently to information from the mass media, based on culture, background, social conditions (Puspita \& Nurhayati, 2018).

Semiotics is one of the most popular topics related to media. The semiotic theory provides a clear picture of what to look for when analyzing the media's meaning or message, explains why media have different effects, allows observers to analyze the structure of media messages without neglecting the public process. This method makes a clear separation between the media and its content. The information contained in each media is essential and depends on the reading provided by the producer or consumer. Semiotics focuses on the way producers create signs and how society, in general, understands these signs.

\section{RESULTS AND DISCUSSION}

\section{A. The Spotlight Film Analysis}

The Spotlight is an American biographical drama film directed by Tom McCarthy, written by McCarthy and Josh Singer, released in 2015. This investigative film work raised the conflict based on a true story in Boston, United States. 
This film is about how the investigative team consisted of 4 journalists from a mass media called Boston Globe, who worked and uncovered the truth by covering the sexual abuse by Catholic priests against children in the church. In the following sections, the core values of journalism will be discussed based on the film's sequences.

In representation and ideology level of John's Fiske's theory, it showed in the film that Boston Globe journalists were under pressure from the Catholic Church as the church had power. It held a solid political and social status in the city. One scene in the film showed two Spotlight team members visiting a Catholic school to dig for information from key faculty members. The situation turned bizarre when asked if the faculty could know what happened when a certain priest who worked at the school faced accusations of harassment. (Drohan, 2016). In the agenda-setting theory, the mass media is believed to not set the public agenda, especially in terms of opinions or attitudes. However, the mass media has specific access in contributing to or influencing society's perceptions, values, focus, and priorities in general. In this case, the church felt threatened by the possibility of getting protests by the public-public because of the pieces of information they would receive from the press. A scene from The Church's side tried to negotiate with The Boston Globe can be seen through the following Image 1:

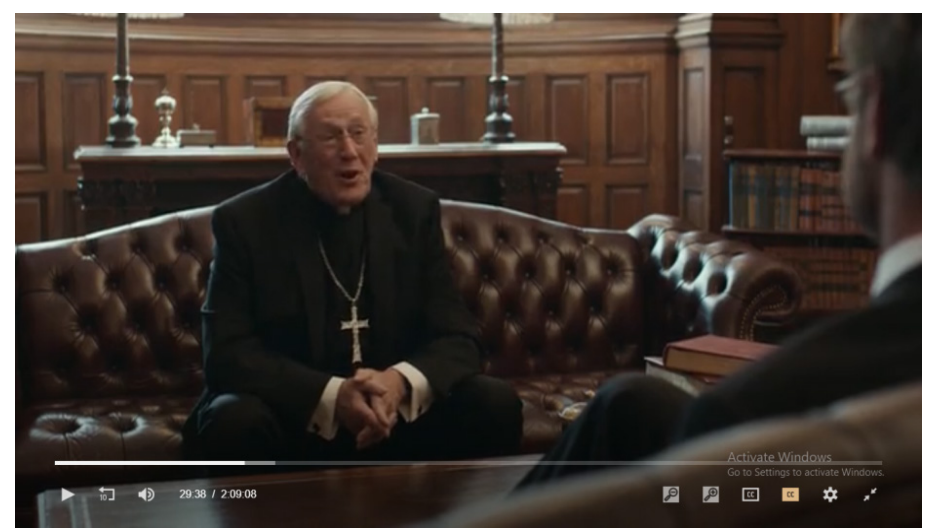

Image 1. Interview scene between The Church and Marty (The Boston Globe's Editor in Chief)

Priest : "I find that the City flourishes when its great institutions work together."

Marty : : "Thank you. Personally, I'm of the opinion that for a paper to best perform its function, it really needs to stand alone."

Priest : : "Ah, of course. But my offer still stands."

Marty : "Thank you."

As Drohan (2016:215) pointed out, the Catholic church's power in Boston was presented throughout the film as various parties from the school boards to lawyers and politicians. The church members tried to convince the Spotlight team that they had better drop the investigation. However, the journalists showed no behavior changes but a solid commitment to their profession and objective reporting by following the findings. In the reality level of John Fiske's theory, the actors showed similarities with the natural environment, appearance, and the way of talking.

The findings were obtained when the Spotlight team examined all priests who had permission to take sick leave or were not assigned to duty. The documents were tracked along with the information about the victims. The facts were then revealed that the sanctions received by priests who carried out sexual harassment were only temporary dismissals from their duties or relocation of duties. Based on the scene, the journalists adopted strategies in doing their duties to maintain the credibility and legitimacy of their coverage. It indicated that the coverage they got was based on facts from credible sources. (Igartua \& Frutos, 2017).

In the ideology level of John Fiske's theory, the public perspective about journalists working based on their individual needs is inevitable by one of the scenes where it showed that the journalist has to work based on the ethic code. He or she needs approval from source people related, whether they want to be recorded or not because they also have the right to share the pieces of information or not. The scene reflected the function of journalists as part of the mass media with its function as observer and values provider. As shown in Image 2, Mike (on the right), one of the Spotlight team members, was rejected by Mr. Grabedian (on the left), a lawyer representing the victims. Mr. Grabedian refused to be a resource as he and Mike conducted an unarranged interview. 


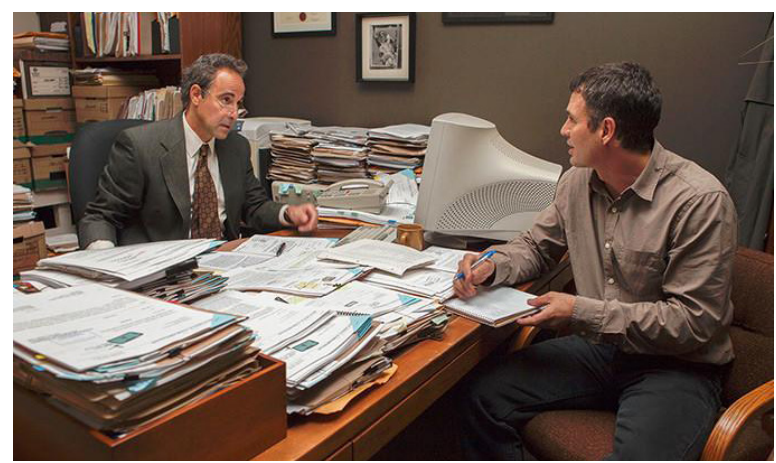

Image 2. Interview Scene Between Mike and Mr. Grabedian

Grabedian : "I can't show you those Church's documents if that's what you're after. They're under seal."

Mike : "Yeah, I know that."

Grabedian : "Did you know that they tried to bring me up before the Massachusetts Board of Bar Overseers three times? They're (The church) watching me very closely. They'd like to get me disbarred."

Mike : (Taking notes)

Grabedian : "Put that away (pointing at the notes), I don't want you recording this in any way, shape, or form. Not on paper, not on tape, nothing. I probably shouldn't even be speaking to you."

Mike told his boss, "I will get it," indicated that if he could not make Mr. Garabedian as a resource in the newspaper, he would approach to carry out the necessary information secretly. In this case, the analysis and decisions taken by the journalist are fundamental. Mike was portrayed as a brusque character but at the same time as a highly motivated journalist who conducted thorough investigations and whose role was to inform the public about the truth.

Moving to the next scene, one of the Spotlight journalists, Sacha, tried to interview by visiting the victims' house and the accused priests. The meeting with Father Paquin, one of the alleged abusers, proved Sacha with more evidence as Paquin admitted the allegations. In the reality level of John Fiske's theory in the previous studies of journalism in a film, a sign had been made about journalists who often met their sources, reporters, in dark alleys. These are the stereotypical views of journalism in films.

As Drohan (2016:214) pointed out, there are several reasons the Spotlight team did not continue the investigation. As suggested, in all levels of John Fiske's theory, the film seemed to portray cultural and institutional tensions and brought them to the table. Starting with a deep ideological setting, The Spotlight emphasized the importance of an individual reporter in the truth-seeking process that ultimately resulted in disclosing information that is often kept secret by those in power. Whereas in real life, journalists rely on routine procedures to verify facts, this film shows journalists relying on alternative and time-consuming sourcing methods.

Later, in a part of the film, Phil Saviano, one of the victims of the sexual abuse, arrived at the Boston Globe and carried a box of materials. During the interview, Phil claimed that he had sent all the material to the Globe five years ago, but the newspapers closed Phil Saviano's case. Journalists intended to base their coverage on the core practice of ensuring balanced and objective coverage with accredited sources. Unfortunately, the material provided by Phil was less objective, which explained why the previous attempt by Saviano to get in touch with Globe was disbanded. The following Image 3 shows the scene of the interview with Phil.

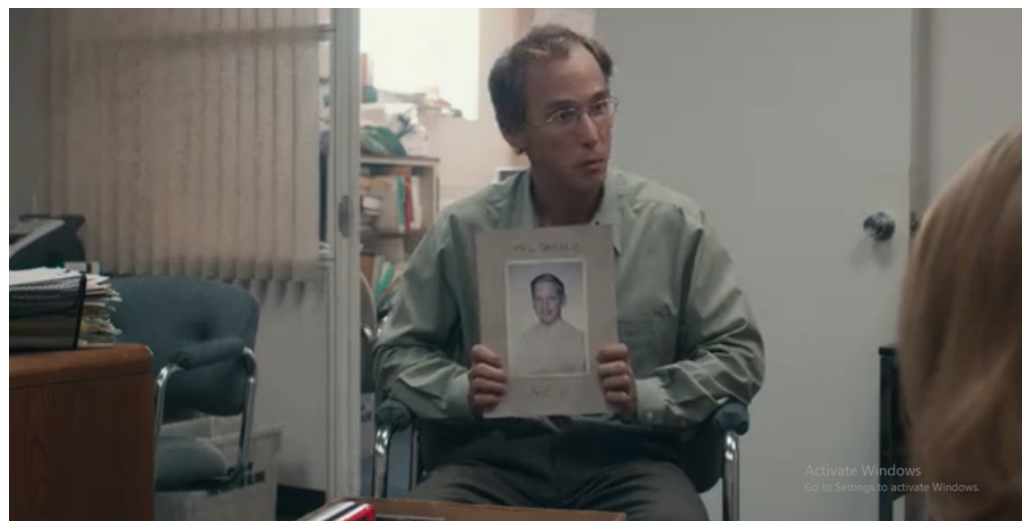

Image 3. Interview Scene between The Spotlight Team and Phil Saviano 


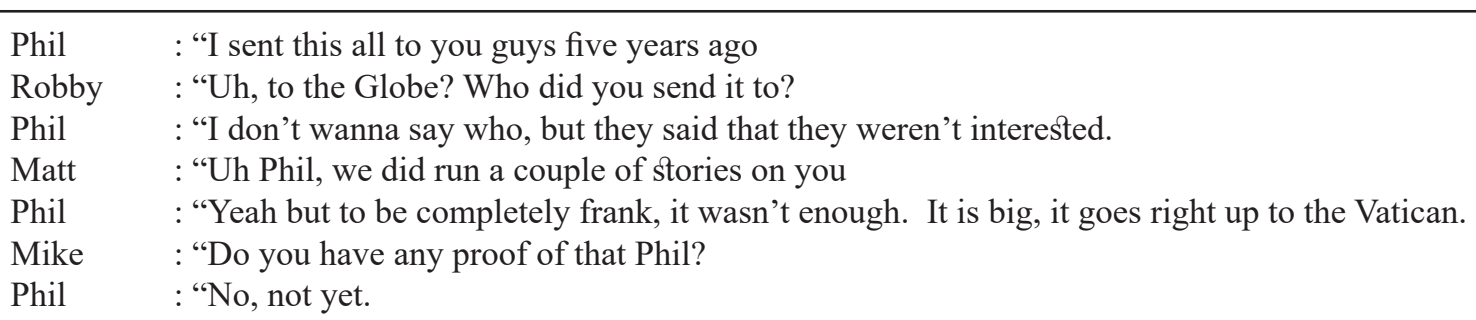

In the ideology level of John Fiske's theory, a journalist must decide what is considered newsworthy and what is finally being reported. It is shown in the court scene to determine whether private documents can be accessed by the public or not. The judge asked Mike, who was present at the time, about the responsibility of journalists if sensitive matters were published to the public. Mike then asked back about where the responsibility of a journalist if it is not published.

At this stage of the film, the entire team had a strong hunch about the newsworthiness of the case. In some scenes, Mike was shown as a journalist who acted as a cynical observer, and these scenes show that he is also intelligent and ready to do anything to reach his source (Ferruci,2018). The judge then gave Mike permission to access the footage.

\section{B. The Representation of Mass Media}

In the analysis above, it can be understood that the material provided by Phil was less objective, which explained why the previous attempt by Savino to get in touch with Globe was disbanded. Although it was considered to be carried out its duties to publish news from accredited sources, if it is elaborated further, that showed how much the media was being cared less about the victims who had no power than the church.

Paul, Singh, and John (2013) explained that the mass media plays a role in conveying information as material for discussion, conveying messages from leaders in the community, and clarifying the problems they convey. At that time, The Boston Globe should have been involved in finding out and clarifying Phil's information.

Although Phil did not have solid evidence, he was a victim and could assist in finding the shreds of evidence. The Boston Globe's choice at that time seemed to be just waiting for the accredited evidence without being involved. It showed the negligence in implementing the media function.

However, when The Spotlight finally had the chance to investigate the case representing The Boston Globe, their colleges from other divisions suggested that it the better to quit, as continuing the investigation means challenging the church. Moreover, the judge handling their charges against the church was a catholic.

In addition, they were faced with two choices, whether they quit covering the case or continue with questions generated about where the media had been all this time. Moreover, Phil had already provided documents related to this case several years before. If the public found out, The Boston Globe would be judged for being negligent in implying mass media function.

The Spotlight team sensed that Savino got an agenda and had been through a lot. Furthermore, if he was right about the information he gave, the real question is where the media had been this whole time? As Paul, Sing, and John (2013) stated, the mass media serves as a provider of information. The function of delivering information can be carried out by the mass media concerned.

Without the participation of the media, the information cannot be conveyed accurately and quickly. The Spotlight then decided to focus on the present time and started to do a background check and follow up with some of the other survivors of his organization, Survivors Network of those Abused by Priests (SNAP). Also, Mike tracked down more priests.

By the end of the film, the team reported on both story sides, a procedure that distinguishes slander from absurdity. In the film, the investigation and gathering of raw materials are based on thorough investigations carried out by the journalists themselves, procedures that journalists tend not to follow in real life due to the lack of time and commitment.

After the first story on the news was released with the accredited pieces of information, The Spotlight generated the public's attention, and surprisingly more victims decided to emerge after holding back the whole time. Throughout 2002, the Spotlight team published close to 600 stories about the scandal. Two hundred forty-nine priests and brothers were publicly accused of sexual abuse within the Boston Archdiocese. The news released by The Boston Globe can be seen in Image 4 following. 


\section{JBoston Sunday Globe}
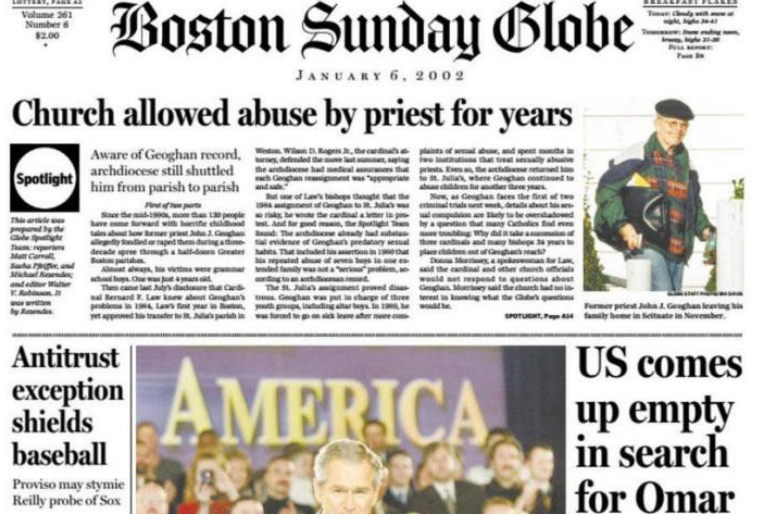

Image 4. One of The Spotlights News on The Boston Sunday Globe

In the reality level of John Fiske's theory, the impact of the dark reality of the church is against Bostonians and around the world. Moreover, the fact that the newspaper was awarded a Pulitzer Prize and the story in this film was made into an award-winning film is invaluable evidence that society still needs newspapers or the mass media to provide checks and balances in democracy as the function of the mass media in general.

In all levels of John Fiske's theory, The Spotlight film showed how the Spotlight Team represented exemplary mass media implementation as the function of mass media. The transmitter of information, aspirations, disseminator of social values, and supervision can be seen from the conflicts and storylines in this film. As Bollinger put it boldly: "The press as the constitution itself recognizes, is a private institution with a public purpose, a systemic function vital to American democracy as the three official branches of government." While it is clear that newspapers as institutions also wield great power to set the agenda through the selection and placement of stories, strong arguments are made in films and other texts.

The Spotlight reinforced the theory that films about journalism can be viewed ideologically in-depth because they show the condition that journalism makes a difference in society and thus helps create an image of journalists as truthseekers and watchdogs of society (Gaitano, 2019). Further, the State of Play in its half highlights stereotypical statements about journalism. This film could demonstrate the ability of journalists to distinguish beliefs and facts through the use of journalistic procedures to enable journalists in the film to claim objectivity.

Based on the analysis above, The Spotlight film showed that the journalists delicately know which information they need. Even the objectivity could not wholly be obtained; the journalists in this film held the practice of professionalism and objectivity in their work. Many critics claim that journalism serves a commercial rather than a moral purpose in the literature, and it is unreasonable to claim the ability to find a particular value in reality (Milan, 2010).

Moreover, it becomes more dangerous for a democratic society to censor the press than to give the press complete freedom to decide what may and may not be printed and believe that journalists working in a professional environment know their responsibilities and respect the journalistic values that are at the core of their profession (Lanosga \& Houston, 2017).

The Spotlight could clearly describe the work of meticulous journalists with methods and make a great statement about the importance of freedom. Not only for the press, but the film also demonstrated the right to have time and resources, be used responsibly in their field of work, and provide a voice for the powerless. This film is an example of the implementations of mass media as agents of support for social change.

The Spotlight film depicted a complex investigative process, as it happened in real life. Everyday journalism relies heavily on the relationship between reporters and officials. The film demonstrated the use of unconventional practices, practices that may place them under the supervision of competent authorities in real life.

\section{CONCLUSION}

In the reality level of John Fiske's theory, The Spotlight showed that journalists base their coverage on accredited sources as their role as a mass media that supports social change with access to reliable news sources, which are then conveyed to the broader community. In journalism practice, it is also known that access to media is more difficult for those who are not part of the elite, as was the case with Phil Savino's previous attempts to contact Globe.

The film relies heavily on toxic news values, best described as journalists' hunches at the ideology level. The Spotlight described an extensive investigative process that most newsrooms do not follow, as modern newsgathering takes place mostly in news agencies and on press releases (Forde \& Johnston, 2013). This film has implemented several functions of the mass media, such as the function of supervision, the function of interpretation, and the function of conveying values. The film also showed the involvement of journalists who function as agents of change in social conditions, as seen in the efforts to uphold justice and resolve conflicts. 
At the representation level, the State of Play further reinforces the media's image and its power. It portrayed the press as heroic and helped legitimize its position as an institution. As shown at the end of the film, the impact of the press is felt, and justice is served. These results further reinforce the notion of solid media and strengthen the role of journalism in film.

\section{REFERENCES}

[1] Bungin, B. (2006). Sosiologi Komunikasi: Teori, Paradigma, dan Diskursus Teknologi Komunikasi di Masyarakat. Jakarta: Kencana Prenada Media.

[2] Drohan, M. (2016). Spotlight And Investigative Journalism: How The Film Reinforces The Essential Role Of A Free, Professional Press In A Democracy. Serials Librarian, 71(3-4), 212-220. DOI:10.1080/0361526X.2016.1237403

[3] Ferrucci, P. (2018). Mo "Meta” Blues: How Popular Culture Can Act as Metajournalistic Discourse. International Journal of Communication, 12, 4821-4838.

[4] Forde, S., \& Johnston, J. (2013). The News Triumvirate: Public Relations, Wire Agencies, And Online Copy. Journalism Studies, 14(1), 113-129. DOI:10.1080/1461670X.2012.679859

[5] Gaitano, N. G. (2019). Objectivity revisited. Church, Communication and Culture, 4(3), 372-375. DOI:10.1080/2 3753234.2019 .1664924

[6] Gillig, T. K., Rosenthal, E. L., Murphy, S. T., \& Folb, K. L. (2018). More than a Media Moment: The Influence of Televised Storylines on Viewers' Attitudes toward Transgender People and Policies. Sex Roles, 78(7-8), $515-527$. DOI:10.1007/s11199-017-0816-1

[7] Green, M. C., \& Clark, J. L. (2013). Transportation Into Narrative Worlds: Implications For Entertainment Media Influences On Tobacco Use. Addiction, 108(3), 477-484. DOI:10.1111/j.1360-0443.2012.04088.x

[8] Habibie, D. K. (2018). Dwi Fungsi Media Massa. Interaksi: Jurnal Ilmu Komunikasi, 7(2), 79-86.

[9] Igartua, J. J., \& Frutos, F. J. (2017). Enhancing Attitudes Toward Stigmatized Groups With Movies: Mediating And Moderating Processes of Narrative Persuasion. International Journal of Communication, 11(1), 158-177.

[10] Jauhola, A. E. (2017). Representation of Investigative Journalism On Film: Comparative Textual Analysis of Two Hollywood Movies' Approach To Journalistic Core Values. Thesis. Orebro University: School of Humanities, Education and Social Sciences.

[11] Kubrak, T. (2020). Behavioral Sciences Impact of Films: Changes in Young People's Attitudes After Watching A Movie. Behavioral Sciences, 10(86), 1-13. DOI:10.3390/bs10050086

[12] Lanosga, G., \& Houston, B. (2017). Spotlight: Journalists Assess Investigative Reporting And Its Status in Society. Journalism Practice, 11(9), 1101-1120. DOI:10.1080/17512786.2016.1228472

[13] Milan, A. (2010). Modern Portrayals of Journalism in Film. Elon Journal of Undergraduate Research in Communications, 1(Spring), 46-57.

[14] Paul, V., Singh, P., \& John, S. B. (2013). Role Of Mass Media In Social Awareness. International Journal of Humanities \& Social Sciences, 1(01), 34-38.

[15] Perciful, M. S., \& Meyer, C. (2017). The Impact of Films on Viewer Attitudes towards People with Schizophrenia. Current Psychology, 36(3), 483-493. DOI:10.1007/s12144-016-9436-0

[16] Puspita, D. F. R., \& Nurhayati, I. K. (2018). Analisis Semiotika John Fiske Mengenai Realitas Bias Gender Pada Iklan Kisah Ramadhan Line Versi Adzan Ayah. ProTVF: Jurnal Kajian Televisi dan Film. 2(2), 157-171. https:// doi.org/10.24198/ptvf.v2i2.20820

[17] Razinah, N., \& Zain, M. (2017). Agenda Setting Theory. International Islamic University Malaysia.

[18] Reaske, C. (1966). How to Analyze Drama. New York: Monarch Press.

[19] Russell, C. A., \& Russell, D. W. (2018). Sensation Seeking Moderates Television's Cultivation of Alcohol And Tobacco Beliefs: Evidence From A National Study Of French Adolescents. Drug and Alcohol Dependence, 186, 193-200. DOI:10.1016/j.drugalcdep.2018.01.031

[20] Saputri, N.A. (2021). Horror Journalism Practices in Jurnalrisa. CHANNEL: Jurnal Komunikasi, 9(1),21-36

[21] Shehata,A., \& Strömbäck, J. (2013). Not(Yet)a New Era of MinimalEffects:AStudy ofAgenda Setting at the Aggregate and Individual Levels. International Journal of Press/Politics, 18(2), 234-255. DOI:10.1177/1940161212473831

[22] Thomas, K. W., Kilmann, R. H., \& Trainer, J. (2010). Thomas - Kilmann Conflict Mode Instrument Competing Assertiveness. Acme, Inc: E-Book.

[23] Yang, F., Salmon, C. T., Pang, J. S., \& Cheng, W. J. Y. (2015). Media exposure and smoking intention in adolescents: A moderated mediation analysis from a cultivation perspective. Journal of Health Psychology, 20(2), $188-197$. DOI: $10.1177 / 1359105313501533$ 